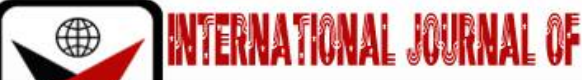

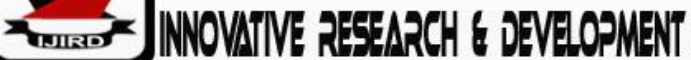

ISSN 2278-0211 (Online)

\section{Mediating Effect of Intention on Attitude to Academic Dishonesty among Undergraduate Students in Public Universities in Ghana}

\author{
Dr. Yayra Dzakadzie
Lecturer, Department of Psychology and Education, University of Education, Winneba, Ghana
Dandy George Dampson
Lecture, Department of Psychology and Education, University of Education, Winneba, Ghana
Peter Eshun
Lecturer, Department of Psychology and Education, University of Education, Winneba, Ghana
}

\begin{abstract}
:
The study was designed to ascertain the mediating effect of intention on attitude toward academic dishonesty among students in public universities in Ghana. The study adopted the survey-inferential design to randomly sample the views of 1,200 university students by structured questionnaire. Pearson Correlation Coefficient and Structural Equation Modelling (SEM) were used for the analyses. It was ascertained that the mediating role of intention produced an indirect effect on attitude to academic dishonesty which was significant. It was concluded that an increase in intention to commit academic dishonesty will lead to an increase in academic dishonesty behaviour. It is recommended that university authorities enforce the rules and regulations against academic dishonesty fully without fear or favour. There should be no sacred cows, all offenders who might condone and connive the menace should be severely punished.
\end{abstract}

Keywords: Intention, attitude, academic dishonesty

\section{Introduction}

Educational institutions have important duties and responsibilities to help form an honest society and to raise individuals with ethical principles (Levy \& Rakovski, 2006). Yet, academic dishonesty is becoming more and more common at every stage of education (Broekelman-Post, 2008). Passow, Mayhew, Finelli, Harding, and Carpenter (2006) posit that academic dishonesty undermines the credibility of learning. It also puts one's integrity at stake. Educational assessment and learning are adversely affected by academic dishonesty (Brimble \& Stevenson-Clarice, 2005), contributing to the development of half-baked graduates (Harding, Carpenter, Finelli \& Passon, 2004). Due to its prevalence among students, academic dishonesty is said to have reached 'epidemic levels' in colleges in United States of America (USA) (McCabe, Trevino \& Butterfield, 2006). Studies conducted among undergraduates in the USA, Korea, Ethiopia, Nigeria among others, found that undergraduates cheat occasionally (Wowra, 2007; Ledesma, 2011, Tadesse \& Getachew, 2010).

Petress (2003) notes that there are many forms of academic dishonesty. These range from copying test answers from friends, taking an examination on behalf of friends (impersonation), failure to cite other people's work (plagiarism), taking examination questions home. Other forms of academic dishonesty include faking research papers and pretending they are one's own work, breaking into the examination office or lecturers' files to access the tests or answer keys, sabotaging peers' work or gaining illegal access into school computers to change official grades. In a related development, Roberts (2002) alleges that plagiarism is another form of academic dishonesty whereby authors tend to manipulate the information in favour of what they want to gain. University of Berkeley Code of Student Conduct (2004) defines plagiarism as the use of intellectual material produced by another person without acknowledging its source in the submission of formal or informal academic assignments. According to the Code this includes, but is not limited to:

- Copying from the writings or works of others into one's academic assignment without proper attribution or submitting such work as if it were one's own;

- Paraphrasing the characteristic or original phraseology, metaphor, or other creative, artistic or literary device of another without proper attribution;

- Using the views or insights of another without proper attribution; or

- Copying, paraphrasing or otherwise using the research data, results, codes, formulae or algorithms of another without proper attribution.

To understand this behaviour (academic dishonesty), Ajzen (1991) claims in his theory of planned behaviour that the motives of the person to perform behaviour must be established in order to predict and explain the behaviour of an 
individual's actions. Ajzen and Fishbein (1980) argue that intentions included variables that showed how committed an individual was to the conduct of a particular action. On the basis of this reasoning, it is anticipated that the greater the motives of an individual, the more likely it is for that individual to undertake a particular action. Purpose is used as a mediator variable in this analysis.

Frazier, Tix, and Barron (2004) conclude that a simple mediation model assumes an intermediate mechanism leading from the predictor variable to the criterion variable. In other words, the predictor is assumed to trigger the mediation in a basic mediational model and, in turn, the criterion variable is triggered by the mediation. The mediation is described by Collins, Graham and Flaherty (1998, 297), as 'a line of dominos knocking over the first domino starts a sequence where the rest of the dominos are knocked over one another'.

In view of this reality, it appears to be more realistic to evaluate behavioural intentions rather than actual behaviour, particularly given the strong connection between intentions and subsequent behaviour (Carpenter \& Reimers 2005). While it has been suggested that behavioural motives are a feature of attitudes, Ajzen and Fishbein (1980) highlighted the fact that the importance of these variables would vary depending on the type of action and circumstances within which the action would be carried out. Curiously, Beck and Ajzen's (1991) study shows how motives play a role among students in committing academic dishonesty (i.e., plagiarism and cheating) and this has set the stage for the current analysis. Indeed, intentions have been linked to attitudes and across a variety of academic dishonesty behaviours (Beck \& Ajzen, 1991; Harding, Mayhew, Finelli\& Carpenter, 2007). Cheating motives were closely associated with cheating activity (Beck \&Azjen, 1991), activity of academic fraud (Stone et al., 2010) and behaviour of academic dishonesty (Harding et al., 2007). Studies have shown that a major indicator of academic dishonesty conduct is the intention to participate in academic dishonesty (Mayhew, Hubbard, Finelli, Harding, \& Carpenter,2009; Stone et al., 2010). Mayhew et al. found that in undergraduate engineering and humanities students, intentions to cheat were strongly linked to cheating behaviour. An important indicator of academic misconduct behaviour has been found to be intention.

In Ghana, University of Ghana (UG), has recorded a wide spread examination malpractice. The principal architect was suspected to be Mr. Kwadzo Tibri Asenso -Okyere, the son of the then Vice-Chancellor, Professor, KwadzoAsensoOkyere. The Vice Chancellor was asked to step aside. The Mfodwo Committee set up to investigate the malpractices,

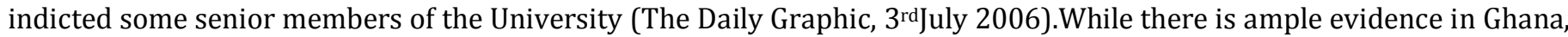
it seems that, except for media accounts, the phenomenon is yet to gain adequate scholarly attention from educational researchers. The purpose of this study is to ascertain the mediation effect of intention on attitude of undergraduate students towards academic dishonesty behaviour in public universities in Ghana.

\section{Hypotheses}

- $\mathrm{H}_{0}$ : there is no statistically significant relationship between attitude toward academic dishonesty and academic dishonesty behaviour among undergraduate students in public universities in Ghana.

- $\quad \mathrm{H}_{1}$ : there is a statistically significant relationship between attitude towards academic dishonesty and academic dishonesty behaviour among undergraduate students in public universities in Ghana.

- $\mathrm{H}_{0}$ : there is no statistically significant relationship between intention and academic dishonesty behaviour among undergraduate students in public universities in Ghana.

- $\mathrm{H}_{1}$ : there is a statistically significant relationship between intention and academic dishonesty behaviour among undergraduate students in public universities in Ghana.

- $\mathrm{H}_{0}$ : There is no statistically significant effect of the mediation effect of intention on attitude towards academic dishonesty among undergraduate students in public universities in Ghana.

- $\mathrm{H}_{1}$ : There is a statistically significant effect of the mediation effect of intention on attitude towards academic dishonesty among undergraduate students in public universities in Ghana.

\section{Method and Material}

The study used a survey-inferential design. Three (3) universities were selected from the five (5) public universities (public universities which are more than 10 years old) using simple random sampling technique. A total of 1,200 students were selected from 22, 458 students across the universities to participate in the study using a table of random numbers method of the simple random sampling technique. Structured questionnaire was developed and used for the study. It consisted of three sections. The first section assessed prevalence of academic dishonesty behaviours with sixteen (16)items. The second section assessed intention to commit academic dishonesty behaviour with five (5) items. The third section assessed attitude of students towards academic dishonesty behaviour with 10 items. All the items were closed-ended items and were polytomously scored. Reliability index for this scale was 0.79.The administration and collection of the instruments were done simultaneously to ensure prompt response and effective delivery from the students. The research hypotheses 1 and 2 were analysed using Pearson Correlation Coefficient whilst hypothesis 3 was analysed with Structural Equation Modelling (SEM).The main variables of interest were academic dishonesty, attitude and intention to engage in academic dishonesty.

\section{Results}

\subsection{Hypothesis 1}

Hypothesis 1, states that 'there is no statistically significant relationship between students' attitude towards academic dishonesty and academic dishonesty behaviour among undergraduate students of public universities in Ghana' was formulated and tested. The results of the Pearson Correlation Coefficient are presented in Table 1. 


\begin{tabular}{|c|c|c|c|}
\hline \multicolumn{2}{|c|}{} & Academic Dishonesty & Attitude \\
\hline \multirow{3}{*}{$\begin{array}{c}\text { Academic } \\
\text { dishonesty }\end{array}$} & Correlation & 1 & \\
\cline { 2 - 4 } & Sig (2-tailed) & 0 & \\
\cline { 2 - 4 } & $\mathrm{N}$ & -.085 & 1.000 \\
\hline \multirow{2}{*}{ Attitude } & Correlation & .000 & 0 \\
\cline { 2 - 4 } & Sig (2-tailed) & 1193 & \\
\cline { 2 - 4 } & $\mathrm{N}$ & & \\
\hline
\end{tabular}

Table 1: Results of Pearson Correlation Coefficient between Attitude and Academic Dishonesty ${ }^{*} P<0.05$ (2-Tailed Significant Results)

Table 1 shows that the correlation between students' attitude and academic dishonesty is-. 085 which is low (Cohen, 1988). This implies that a weak negative relationship existed between attitude towards academic dishonesty and academic dishonesty. Though a weak relationship, it reveals that as students' attitude towards academic dishonesty increases, there is a minimal increase in their ability to indulge in academic dishonesty. In other words, as students hold positive attitude towards academic dishonesty, they are likely to engage in academic dishonesty but when they hold negative attitude towards academic dishonesty, they are not likely to engage in academic dishonesty. This is an inverse relationship. As a result, the null hypothesis that there is no statistically significant relationship between students' attitude towards academic dishonesty and academic dishonesty behaviour among undergraduate university students in Ghanais rejected.

To ascertain how much variance, the attitude towards academic dishonesty and academic dishonesty shared, the coefficient of determination was calculated to be 0.007225 which indicates that, $0.72 \%$ shared variance. Thus, attitude towards academic dishonesty helps to explain 0.72 percent of the variance in students' actual academic dishonesty behaviour.

\subsection{Hypothesis 2}

Hypothesis 2 which states 'there is no statistically significant relationship between intention and academic dishonesty among undergraduate students in public universities in Ghana' was also formulated and tested. The results of the Pearson Correlation Coefficient are presented in Table 2:

\begin{tabular}{|c|c|c|c|}
\hline \multicolumn{2}{|c|}{} & Academic Dishonesty & Attitude \\
\hline \multirow{3}{*}{$\begin{array}{c}\text { Academic } \\
\text { dishonesty }\end{array}$} & Correlation & 1 & \\
\cline { 2 - 4 } & Sig (2-tailed) & & \\
\cline { 2 - 4 } & $\mathrm{N}$ & 0 & 1.000 \\
\hline \multirow{3}{*}{ Intention } & Correlation & .265 & \\
\cline { 2 - 4 } & Sig (2-tailed) & .000 & 0 \\
\cline { 2 - 4 } & $\mathrm{N}$ & 1193 & \\
\hline
\end{tabular}

Table 2: Results of Pearson Correlation Coefficient between Intention and Academic Dishonesty ${ }^{*} p<0.05$ (2-tailed significant results)

Table 2 shows that the correlation between students' intention and academic dishonesty is .265 which is small (Cohen, 1988). This implies that a weak positive relationship existed between intention towards academic dishonesty and academic dishonesty. It reveals that as students' intention towards academic dishonesty increases, their academic dishonesty behaviour increases. In other words, as students hold high intention towards academic dishonesty, they are likely to engage in academic dishonesty. As a result, the null hypothesis that there is no statistically significant relationship between students' intention towards academic dishonesty and academic dishonesty behaviour among undergraduate university students in Ghanais rejected.

To ascertain how much variance, the intention towards academic dishonesty and academic dishonesty shared, the coefficient of determination was calculated to be 0.07 which indicates $7 \%$ shared variance. Thus, intention towards academic dishonesty helps to explain 7percent of the variance in students' actual academic dishonesty behaviour.

\subsection{Hypothesis 3}

Hypothesis 3 which states 'There is no statistically significant effect of the mediation effect of intention on attitude towards academic dishonesty among undergraduate students in public universities in Ghana. Results for the structural model assessment on the mediation effect of intention on the relationship between attitude and academic dishonesty are presented in Table 3 and Fig. 1. 


\begin{tabular}{|c|c|c|c|c|}
\hline Source of Variation & Relationship & Path Estimate & t- statistics & p-value \\
\hline & Attitude $\rightarrow$ AD & -0.085 & 2.194 & 0.027 \\
\hline & Attitude $\rightarrow$ int & -0.228 & 5.840 & 0.000 \\
\hline Total effect & Int $\rightarrow$ AD & 0.265 & 7.617 & 0.000 \\
\hline Indirect effect & Attitude $\rightarrow$ AD & -0.061 & 4.590 & 0.000 \\
\hline VAF & 0.421 & & & \\
\hline
\end{tabular}

Table 3: SEM Parameter Estimate on the Mediating Effect of Intention on the Relationship between Attitude and Academic Dishonesty

Note: VAF=indirect effect/ (Direct effect + indirect effect). * sig at $\alpha=5 \%$.

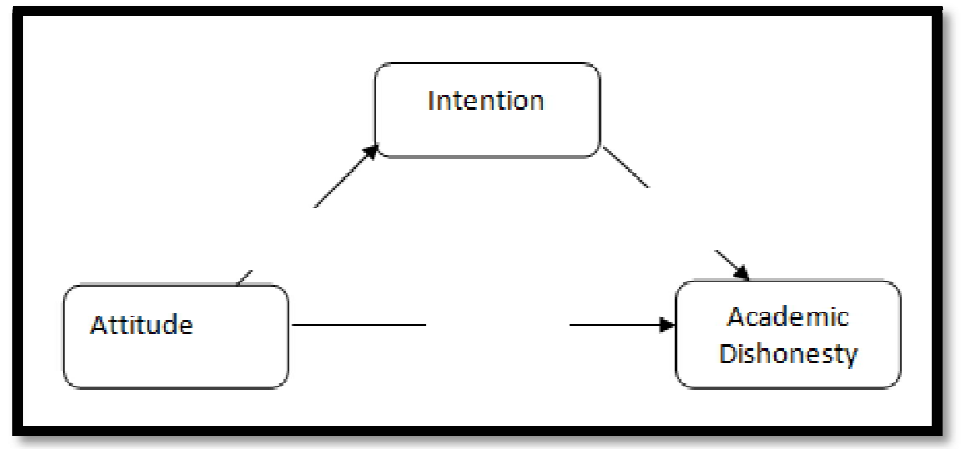

Figure 1: Mediating Effect of Intention On Attitude To Academic Dishonesty

Table 1and Fig. 1, the direct effect of attitude on academic dishonesty was negative but it was however significant $(\mathrm{r}=-.28, \beta=0.085, \mathrm{p}=0.027)$. The mediating role of intention in the model produced an indirect effect on academic dishonesty which was also significant $(r=-.54, \beta=0.61, p=0.00)$. Hair, Black propose that the variance accounted for (VAF) should be greater than 0.2 for mediating effects to be considered. VAF values greater than 0.2 but less than 0.8 would be regarded as partial mediation in this analysis, whereas values greater than 0.8 would be regarded as complete mediation. Again, to establish the total variance accounted for (VAF) by attitude in academic dishonesty behaviour, mediating effect of intention on the relationship between attitude and academic dishonesty was analyzed.

Again, the result in Table 1 and Fig. 2 shows that intention was mediating the relationship between attitude and academic dishonesty. However, it could be seen that the mediating effect was partial since Variance Accounted For (VAF) which is $0.42(42 \%)$ was less than $0.8(80 \%)$. The practical implication of this result is that improving Attitude $\rightarrow$ Intention and Intention $\rightarrow$ Academic Dishonesty links would lead to an improvement in the Attitude $\rightarrow$ Academic Dishonesty link. This implies that when students' attitude is negative (higher scores) the intention to commit academic dishonesty decreases. In the same way when students hold favourable attitude towards academic dishonesty (low score or the same score), intention to engage in academic dishonesty increases.

\section{Discussion}

The importance of attitude and its relationship with behaviour cannot be over-emphasised. Societal attitude towards a behaviour gives room to the individual and other members of the society to repeat or extinct the behaviour. It is obvious from the result that university students' attitude towards academic dishonesty behaviour is likely to nurture or discourage the occurrence of academic dishonesty. The outcome of this study is consistent with that of previous research on academic cheating which often shows that people are more likely to participate in cheating activities that they consider as less extreme (McLaughlin \& Ross, 1989). Lim and See (2001) study on undergraduates in Singapore found a correlation index of -.20 between students' attitude towards cheating and their actual cheating behaviour. This finding agrees with Harding et al.'s (2007) study, which reports a statistically significant correlation coefficient of .39 between the attitude towards academic dishonesty and dishonesty behaviour (i.e., cheating) of undergraduate students. The finding also collaborates Beck and Ajzen's (1991) study that report a statistically significant correlation coefficient of .22 on 146 undergraduate Psychology students' cheating behaviour and their attitude towards cheating. It should be noted that attitude denotes the sum of a person's feelings, ideas, fears and threats about a specific phenomenon (Oppenheim, 1992), hence the result is not surprising.

The result implies that a rise in intention to commit academic dishonesty will lead to an increase in academic dishonesty. This confirms Carpenter \& Reimers (2005) study where a strong relationship between intention and behaviour, with intention as a function of attitude. It is understandable that when students place favourable attitude towards academic dishonesty, their intention will increase with the belief that academic dishonesty will occur and vice versa. The result is consistent with Whitley's (1998) research that showed students with favourable attitudes to academic dishonesty were more likely than students with unfavourable attitudes to participate in academic dishonest behaviour. Again, the finding is consistent with studies by Hardigan (2004), Magnus, Polterovich, Danilov, and Savvateev(2002)and Harding et al (2007). They also found that students who had a favourable attitude towards academic dishonesty engaged in it several times. One explanation for this finding is that, attitude denotes the sum of man's inclinations and feelings, ideas, fears and threats about a specific behaviour (Oppenheim, 1992). It is an indication that prediction becomes accurate 
depending on how strong attitude is, and how directly relevant the attitude is to behaviour or situation. Clearly, student's attitude towards academic dishonesty will give room to repeating or extinction of the menace. Therefore, the statistical significance of mediating effect on attitude in predicting academic dishonesty shows that the attitudes of the students are most likely to nurture or threaten academic dishonesty in the universities.

\section{Conclusion and Recommendations}

The indirect relationship between the predictor and the mediating variable yielded appreciable results. However, the mediator variable (intention) had a partial relationship between the exogeneous variable (attitude) and the endogenous variable (academic dishonesty). Based on this conclusion, it is recommended that university authorities should enforce the rules and regulations against academic dishonesty fully without fear or favour. There should be no sacred cows, all offenders, including students, and others university staff who might condone and connive the menace should be severely punished. As part of the punishment, the university authorities should intensify publication of names and pictures of culprits who are involved in academic dishonesty in the national media, university notice boards and all public places to minimise positive attitude toward academic dishonesty, intention to engage in academic dishonesty and committing academic dishonesty.

\section{References}

i. Ajzen, I. (1991). The theory of planned behaviour. Organizational Behaviour and Human Decision Processes, 50(2), 179-211.

ii. Ajzen, I., \& Fishbein, M. (1980). Understanding attitudes and predicting social behaviour. Englewood Cliffs, New Jersey: Prentice-Hall.

iii. Beck, L., \& Ajzen, I. (1991). Predicting dishonest actions using the theory of planned behaviour. Journal of Research in Personality, 25(3), 285-301.

iv. Brimble, M., \& Stevenson-Clarke, P. (2005). Perceptions of the prevalence and seriousness of academic dishonesty in Australian universities. Australian Educational Researcher, 32(3), 19-44.

v. Broeckelman-Post, M. A. (2008). Faculty and student classroom influences on academic dishonesty. IEEE Transactions on Education. 51(2) 206-11.

vi. Carpenter, T. D., \& Reimers, J. L. (2005). Unethical and fraudulent financial reporting: Applying the theory of planned behaviour. Journal of Business Ethics, 60, 115-129.

vii. Cohen, J. (1988). Statistical power analysis for the behavioural sciences (2nd ed.). Hillsdale, NJ: Erlbaum.

viii. Collins, L. M., Graham, J. J. \&Flaherty, B. P. (1998) An Alternative Framework for Defining Mediation. Multivariate Behavioural Research, 33(2), 295-312.

ix. Frasier, P.A., Tix, A.P., \& Barron, K.E. (2004). Testing moderator and mediator effects in counselling psychology research. Journal of Counselling Psychology, 51(1), 115-134.

x. Hair, J. F., Black, W. C., Babin, B. J., \& Anderson, R. E. (2014). Multivariate data analysis (7th ed.). Essex: Pearson Education International.

xi. Hardigan, P. (2004). Third-year pharmacy students' attitudes toward cheating behaviours. American Journal of Pharmaceutical Education, 68(5), 1-5.

xii. Harding, T., Carpenter, D., Finelli C., \&Passow, H. (2004). Does academic dishonesty relate to unethical behaviour in professional practice? An exploratory study. Science and Engineering Ethics, 10(2), 311-326.

xiii. Harding, T., Mayhew, M., Finelli, C., \& Carpenter, D. (2007). The theory of planned behaviour as a model of academic dishonesty in humanities and engineering undergraduates. Ethics \& Behaviour, 17(3), 255-279.

xiv. Ledesma, R. (2011). Academic dishonesty among undergraduate students at a Korean university. Research in World Economy, 2(2), 25-35.

xv. Lim, V.K.G., \& S.K.B. See (2001). Attitude toward, and intentions to report, academic cheating among students in Singapore. Ethics and Behaviour11, (3), 261-74.

xvi. Levy, E. S. \&Rakovski, C. C. (2006). Academic dishonesty: a zero-tolerance professor and student registration choices. Research in Higher Education, 47(6), 735-54.

xvii. Magnus, J., Polterovich, V., Danilov, D., \&Savvateev, A. (2002). Tolerance of cheating: An analysis across countries. Journal of Economic Education, 33(2), 125-135.

xviii. Mayhew, M. J., Hubbard, S. M., Finelli, C. J., Harding, T. S., \& Carpenter, D. D. (2009). Using structural equation modelling to validate the theory of planned behaviour as a model for predicting student cheating. The Review of Higher Education, 32(4), 441- 468.

xix. McCabe, D., Trevino, L., \& Butterfield, K. (2006). Academic dishonesty in graduate business programs: Prevalence, causes, and proposed action. Academy of Management Learning \& Education, 5(3), 294-305.

xx. McLaughlin, R. D., \& Ross, S. M. (1989). Student cheating in high school: A case of moral reasoning vs. 'fuzzy logic.'High School Journal, 73(3), 97-104.

xxi. Murdock, T., \& Anderman, E. (2006). Motivational perspectives on student cheating: Toward an integrated model of academic dishonesty. Educational Psychologist, 41(3), 129-145.

xxii. Oppenheim, A. N. (1992). Questionnaire design, interviewing and attitude measurement. New York: Pinter Publishers.

xxiii. Passow, H. J., Mayhew, M. J., Finelli, C. J., Harding, T. S., \& Carpenter, D. D. (2006). Factors influencing engineering students' decisions to cheat by type of assessment. Research in Higher Education, 47(6), 643-684. 
xxiv. Petress, K. C. (2003). Academic dishonesty: A plague on our profession. Education, 123 (3), 624.

$x x v$. Roberts, E. (2002). Strategies for promoting academic integrity in CS course. 32nd Annual Frontiers in Education, 3. Retrieved on 12/11/2015 from http://dx.doi.org/10.1109/FIE.2002.1158209.

xxvi. Stone, T. H., Jawahar, I. M., \& Kisamore, J. L. (2010). Predicting academic misconduct intentions and behaviour using the theory of planned behaviour. Basic and Applied Psychology, 32, 35-45.

xxvii. Tadesse, T., \& Getachew, K. (2010). An exploration of undergraduate students' self-reported academic dishonesty at Addis Ababa and Jimma Universities. Ethiopian Journal of Education and Sciences, 5, 79-99.

xxviii. Whitley, B. (1998). Factors associated with cheating among college students: A review. Research in Higher Education, 39(3), 235-274.

xxix. Wowra, S. A. (2007). Academic dishonesty. Ethics \& Behaviour, 17(3), 211-14. 